\title{
SOBRE DIVERSÃO E AVENTURA NO TURISMO: DISCIPLINA, CONSUMO, INFANTILIZAÇÃO
}

\author{
ON FUN AND ADVENTURE IN TOURISM: \\ DISCIPLINE, CONSUMPTION, INFANTILIZATION
}

\section{SOBRE DIVERSIÓN Y AVENTURA EN EL TURISMO: DISCIPLINA, CONSUMO, INFANTILIZACIÓN}

Verônica Werle ${ }^{1}$; Alexandre Fernandez Vaz $^{2}$

\section{RESUMO}

Amparados pelo conceito crítico de Indústria Cultural tensionamos noções de aventura e diversão que circunscrevem o imaginário sobre as viagens modernas, em especial aquelas organizadas sob o modelo turístico. Para tanto, acompanhamos 4 excursões realizadas na Região Sul do Brasil e entrevistamos 15 turistas. Os resultados apontam que: a segurança proporcionada pela excursão dificulta o encontro com o novo e o distinto, inerentes à aventura; os mecanismos disciplinadores do turismo promovem um tipo de diversão orientada a qual os turistas subordinam-se voluntariamente. Ao garantir a diversão e combater a aventura, o turismo infantiliza os viajantes, determinando experiências enrijecedoras das suas potencialidades subjetivas.

PALAVRAS-CHAVE: Turismo. Indústria Cultural. Infantilização.

\begin{abstract}
Supported by the critical concept of Cultural Industry we intend to put in question the notions of adventure and fun that circumscribe the modern travel imaginary, including those organized under the tourist model. For this, we followed-up four excursions in Southern Region of Brazil and interviewed 15 tourists. The results show that: the security provided by excursion difficult meeting with the new and the other, both inherent to adventure; tourism provides disciplining mechanisms, promotes a kind of oriented fun that tourists voluntarily subordinate themselves to. By ensuring fun and discourage adventure, tourism infantilizes travelers, determining stiffening subjective experiences.
\end{abstract}

KEYWORDS: Tourism. Cultural Industry. Infantilization.

\section{RESUMEN}

Orientados por el concepto crítico de industria cultural, ponemos bajo tensión las nociones de aventura y diversión que como que dan contorno al imaginario sobre los viajes modernos, en especial los organizados bajo el modelo turístico. Para tanto, estuvimos en cuatro excursiones realizadas en la región sur de Brasil, entrevistando quince turistas. Los resultados obtenidos sugieren que: la seguridad de la excursión dificulta el encuentro con lo nuevo y el distinto, inherente a la aventura; los mecanismos disciplinares del turismo promueve un tipo de diversión orientada a la cual los turistas voluntariamente se sujetan. Al garantizar la diversión y

\footnotetext{
${ }^{1}$ Doutora em Educação - Universidade Federal de Santa Catarina - Universidade Federal de Santa Catarina (UFSC) - Florianópolis, SC - Brasil. Professora da Universidade Federal do Paraná (UFPR) - Curitiba, PR - Brasil. Email: vewerle@yahoo.com.br

${ }^{2}$ Doutor em Ciências Humanas - Leibniz Universität Hannover - Hannover, Alemanha. Professor - Universidade Federal de Santa Catarina (UFSC) - Florianópolis, SC - Brasil. E-mail: alexfvaz@uol.com.br
}

Submetido em: 15/01/2018 - Aceito em: 24/08/2018 
combatir la aventura, el turismo infantiliza los viajeros, determinando experiencias endurecidas de sus potencias subjetivas.

PALAVRAS-CLAVE: Turismo. Industria Cultural. Infantilización.

\section{INTRODUÇÃO}

Da Antiguidade até, pelo menos, o século XVII, viajar esteve fundamentalmente relacionado a fins essencialmente práticos, realizando-se em função de necessidades de cumprimento de atividades estatais e diplomáticas, para peregrinação religiosa e principalmente por motivos comerciais (ROMANO, 2013). O deslocamento humano no espaço, alheio às necessidades objetivas da vida, ganha expressão somente ao final do século XVIII, por meio da prática do Grand Tour, caracterizada por longas viagens realizadas como parte da educação burguesa dos filhos da elite europeia, de onde provém a palavra turismo (ROMANO, 2013). Com as transformações técnicas e sociais, a prática do Grand Tour vai se reconfigurando, expandindo-se para camadas sociais menos abastadas. O costume é difundido entre diversos países europeus e nos Estados Unidos da América, fazendo emergir o turismo de massa nos séculos XIX e XX.

Neste contexto, o turismo trouxe a viagem ao círculo ampliado da mercadoria para ser consumida no tempo liberado do trabalho (AMBRÓZIO, 2005). As viagens, convertidas em turismo, hoje, são apresentadas e recebidas como esperança de felicidade em contrapartida às agruras do tempo de trabalho - como, aliás, de forma geral, colocam-se as práticas de lazer. Participam, portanto, do processo de reprodução capitalista e ao contrário de livre fruição ou exercício da vontade, caracterizam-se, em grande medida, pela ilusão da possibilidade de escolha (ADORNO, 2015). Sendo objeto de desejo e de consumo privilegiado no rol das práticas de entretenimento, as viagens estão cada vez mais acessíveis no mercado do entretenimento, na forma de pacotes, excursões e passeios turísticos.

Entre as promessas das viagens mercantilizadas estão a aventura e a diversão que constituem o universo simbólico das expectativas e experiências que circunscrevem essas atividades de 'tempo livre'. No entanto, o prazer, a surpresa agradável da descoberta, os momentos de deleite que estão colados à imagem da viagem contemporânea encontram pouco eco em seus correspondentes históricos ${ }^{3}$ e, não raro, apresentam-se como disfarces para mascarar o caráter normatizador e mercantil da viagem.

\footnotetext{
${ }^{3}$ É exemplo a Odisseia, de Homero, que narra a viagem de Ulisses de volta para casa, após a Guerra de Tróia, da qual não queria participar. Embora Ulisses seja a imagem mítica de todos os futuros viajantes, explica Enzensberger (1985), ele mesmo se caracteriza como sofredor ao longo do poema. Os problemas que enfrentou no decurso da viagem não teriam o sentido positivo de aventura 'a priori', muito menos este era o objetivo da viagem, ao contrário, tratava-se de um deslocamento compulsório, longo e cansativo, para o reencontro com a família, marcado pelo sofrimento e pela solidão.
}

(C) ETD-Educação Temática Digital Campinas, SP $\quad$ v.21 n.1 $\quad$ p.164-181 jan./mar. 2019 
Ao descrevermos o funcionamento de alguns mecanismos da indústria turística ${ }^{4}$, objetivamos mostrar (não) lugares da aventura e da diversão na configuração da viagem como mercadoria e algumas de suas implicações na formação subjetiva. Nisso, ganha importância a disciplina e a previsibilidade próprias da Indústria Cultural, materializadas na diversão orientada, consentida e desejada pelos turistas consumidores e que, não raro, os conduz a uma condição infantilizada de negação da própria capacidade de julgamento sobre aquilo que encontram na viagem. Se tais elementos são assim visíveis no turismo é porque este reproduz o espírito do tempo, no qual a diversão, acompanhada pelo esquecimento e pelo assujeitamento, constitui-se em um dever e um modelo de lazer que se tornou hegemônico.

A análise foi realizada a partir do acompanhamento de quatro viagens realizadas em forma de excursão, portanto, com roteiro e programação pré-estabelecidos para um grupo de turistas. Trata-se de uma forma econômica e fácil de viajar, já que não é necessário esforço em relação a reservas, itinerários ou transportes. Foram acompanhadas 4 excursões, com aproximadamente 30 pessoas em cada uma delas, com duração de 2 a 4 dias, saindo de Florianópolis para destinos localizados na Região Sul do Brasil. Os dados produzidos ao longo das viagens compreendem as falas e expressões corporais dos turistas, além das impressões dos pesquisadores, sendo estes registrados em diário de campo. Também foram entrevistados 15 turistas, em sua maioria idosos, a partir de um roteiro semiestruturado e da gravação seguida de transcrição e análise dos dados ${ }^{5}$.

As excursões fazem parte do Programa de Turismo Social do Serviço Social do Comércio (SESC) de Santa Catarina, que existe desde a década de 1990 e, em correspondência com a proposta de institucionalização organizada e educativa do 'tempo livre' da entidade, objetiva oferecer viagens turísticas a custos reduzidos, especialmente para seus associados, trabalhadores do comércio de bens e serviços, bem como a homens e mulheres acima de 60 anos.

\footnotetext{
${ }^{4}$ A despeito das especificidades do turismo, a ele são empregadas as mesmas estratégias de produção e estímulo ao consumo que os demais produtos culturais mercantilizados, conforme ensinam Horkheimer e Adorno (2015) por meio do conceito de indústria cultural. Este refere-se a um sistema de reprodução e dominação social que envolve o simulacro de diferenciação dos produtos, a manipulação retroativa dos consumidores com a produção de desejos e necessidades, o treinamento dos sentidos por meio do uso de clichês e do gozo pela repetição do sempre igual.

${ }^{5}$ A pesquisa foi aprovada pelo Comitê de Ética da Universidade do Sul de Santa Catarina - UNISUL conforme parecer 1.017.249. O Termo de Consentimento Livre e Esclarecido - TCLE foi assinado pelos turistas que aceitaram livremente participar do estudo.
}

(C) ETD-Educação Temática Digital Campinas, SP $\quad$ v.21 n.1 $\quad$ p.164-181 jan./mar. 2019 
Inicialmente, apresentamos algumas notas sobre o conceito de aventura, sua relação com o ideário de modernidade e o turismo como prática social que promete a vida aventureira. Na sequência, a partir dos dados empíricos, apresentamos a impossibilidade de o turismo realizar-se como aventura devido ao alto grau de segurança e previsibilidade que encontra em seu formato. Posteriormente, enfatizamos o caráter de diversão orientada e normatizada do turismo, destacadamente entre idosos, o que se constitui em obstáculo ao pensar e agir autônomos.

\title{
2 AVENTURA, MODERNIDADE, TURISMO.
}

\begin{abstract}
Aventura? Segundo o Oxford English dictionary, no inglês da Idade Média, essa palavra significava qualquer coisa que ocorrera sem planejamento - por acaso, acidente, sorte. Também significava um acontecimento cheio de perigo ou uma ameaça de perda: risco, prejuízo; um empreendimento arriscado ou uma proeza infeliz. Mais tarde, perto dos tempos modernos, "aventura" passou a significar arriscar-se: uma ousadia ou um experimento - um esforço insólito ou excitante, jamais tentado (BAUMAN, 2006, p. 7-8).
\end{abstract}

$\mathrm{Na}$ citação acima, podemos identificar algumas mudanças e permanências no significado do termo aventura. Inicialmente, estava relacionado com algo não planejado, perigoso e não desejável, poderíamos imaginar um deixar-se cair na completa escuridão, sem qualquer garantia de retorno, ou um lançar-se ao mar sem instrumentos de navegação, como fizeram os antigos exploradores. Posteriormente, o perigo é substituído pelo risco calculado e controlado e a aventura passa a ter um sentido positivo, de colocar-se diante de uma situação de potencial ameaça ou tensão, mas de forma segura. Somente a partir da condição de controle dos riscos é que podemos falar de aventura em sentido positivo, de uma situação que nos coloca em tensão, mas não em perigo propriamente. Assim sendo, faz sentido nomearmos como aventura a realização de um experimento científico ousado, bem como a escalada esportiva de uma montanha ou uma viagem a um lugar por nós desconhecido, o que nos colocaria diante de algo incomum, exigindo-nos um novo comportamento, um novo olhar, uma nova experiência.

Se é na Modernidade que o ideário de aventura positivada é construído é porque ela mesma é, segundo Berman (1987), símbolo de aventura e progresso. Assim como a palavra aventura, do latim adventure, significa "as coisas que estão por chegar" num sentido de movimento, de aproximação com situações incertas que estão por vir ${ }^{6}$, os sentidos de modernidade e do ser moderno também são orientados para o que está por vir, são guiados pela promessa do novo e pela esperança em um futuro que, mesmo que incerto, julga-se que será melhor.

\footnotetext{
${ }^{6}$ A etimologia da palavra aventura e de outras mais pode ser encontrada no dicionário etimológico online <http://www.etimologias.dechile.net>.
}

C ETD- Educação Temática Digital Campinas, SP $\quad$ v.21 n.1 $\quad$ p.164-181 jan./mar. 2019 
Mas a concepção de Modernidade como aventura, bem como das experiências deste período deve-se ao fato de que, nela, estabeleceram-se as condições para que se pudesse conhecer o novo aparentemente com segurança, não apenas devido aos avanços técnicos que proporcionaram conforto e controle do risco, mas também à consolidação do pensamento técnico racional cuja promessa era fornecer um tipo de conhecimento seguro e verdadeiro, considerado capaz de conduzir a humanidade ao progresso, à liberdade e ao esclarecimento.

Sabe-se, no entanto que, ao mesmo tempo em que se instauravam os novos princípios orientadores e ordenadores da vida social, o projeto de modernidade promoveu uma ruptura com antigas tradições e com rígidos padrões morais e religiosos, desencadeando experiências, ambientes e relações marcadas pela descontinuidade e pela instabilidade, de modo que "Ser moderno é encontrar-se em um ambiente que promete aventura, poder, alegria, crescimento, autotransformação e transformação das coisas em redor - mas ao mesmo tempo ameaça destruir tudo o que temos, tudo o que sabemos, tudo o que somos" (BERMAN, 1987, p. 15).

O ambiente que prometia a aventura moderna foi, em boa medida, o urbano - mesmo quando se fala em natureza, esta é uma construção da experiência da cidade -, no qual emergiram novas práticas sociais. Neste contexto, o turismo representou duplamente o ideário de aventura, primeiramente por fazer parte das práticas de lazer que simbolizavam os valores modernos de inovação social e cultural e, também, por possibilitar o contato com outras paisagens, culturas e povos desconhecidos com uma segurança jamais antes experimentada.

Os maiores níveis de especialização dos profissionais ligados ao turismo e os avanços na infraestrutura hoteleira atenuaram antigas situações de perigo inerentes às viagens. A certeza de encontrar hospedagens, alimentação, guias impressos e profissionais capazes de realizar rapidamente qualquer serviço necessário (e desnecessário) ao turista diminuíram o alto grau de imprevisibilidade que a viagem tradicional oferecia. A esses novos elementos, acrescentamos os confortáveis e velozes meios de transporte, a abertura de boas estradas, ferrovias e portos, as formas instantâneas de registro de imagens, a acessibilidade da informação, entre outros aspectos que vão conduzindo os sentidos e a produção de subjetividades de forma qualitativamente diferente daquela experimentada nas clássicas viagens.

Diferentes de um 'mal necessário', como eram consideradas as viagens tradicionais especificamente aquelas realizadas com fins essencialmente práticos - devido aos desgastes físicos provocados pelas péssimas condições de estradas, transportes e dos perigos naturais e 'humanos' (ENZENSBERGER, 1985), as viagens de puro divertimento como as que conhecemos hoje são extremamente seguras e confortáveis. Enzensberger (1985, p. 216) observa o turismo como algo paradoxal, pois o turista almeja, ao mesmo tempo, o atingível e 
o inacessível, o "distante da civilização, mas confortável". O turista pode conhecer animais selvagens da savana africana em cima de jipes, filmar a Cordilheira dos Andes por teleférico, ou, como em um dos casos investigados, observar resquícios da 'arquitetura germânica em Pomerode, Santa Catarina, através da janela do ônibus e da temperatura agradável do ar condicionado.

\section{SEGURANÇA E PREVISIBILIDADE: O TURISMO PARA ALÉM DO CONTROLE DOS RISCOS EXTERNOS E O ANIQUILAMENTO DA AVENTURA.}

Se as viagens de turismo são experiências cada vez mais seguras, no caso daquelas organizadas como excursão isso se intensifica. As medidas de segurança, muitas vezes imperceptíveis, circunscrevem toda a viagem, desde a assinatura do contrato até o retorno do turista à sua residência. Informações sobre medicamentos, doenças, alergias, telefones de familiares, convênios médicos, reserva de dinheiro, bem como o comprometimento em "cumprir o itinerário preestabelecido pelo SESC" (SESC, 2014, p. 3), devendo qualquer mudança ser avisada previamente, são elementos requeridos e exigidos do turista no momento da assinatura contratual. Ao mesmo tempo, a instituição promotora da excursão assegura um profissional para "acompanhar, orientar e conduzir os grupos durante a programação dos passeios" (SESC, 2014, p. 2).

Para os turistas, essa segurança, ao mesmo tempo fornecida e exigida, é um componente importante para a escolha de viajar em excursão, pois, como diz Camila (Funcionária Pública, 51 anos) "Tu já sai daqui com roteiro pronto, com hotel que vai ficar, os guias são treinados, apesar de pegar alguns que não eram tão bons." Da mesma forma, Edson (Estudante, 24 anos) explica que prefere a viagem em excursão, pois, do contrário, seria "muito chato se incomodar para organizar tudo, o hotel seria mais caro também. E se desse algum problema seria a gente que teria que resolver, se desse problema com hotel ou transporte também."

Juntamente à preocupação com a integridade física dos turistas, é implícita uma preocupação em prevenir sentimentos de frustração, esforço ou desconforto, o que é evitado por meio da recepção individualizada de cada um no momento do embarque, dos ajustes e das trocas de pessoas nos assentos, da mudança de itinerário quando acordado pela maioria, do tratamento pessoalizado e do tom de intimidade promovido pelo guia e demais profissionais, como recepcionistas, motoristas e garçons. Esse aspecto também é evidente e valorizado pelos turistas, como diz Camila (Funcionária Pública, 51 anos): "O SESC tem o cuidado de tentar agradar a todos de maneira geral, a gente sente que eles fazem as coisas com carinho e fazem de tudo para agradar, apesar dos programas serem fechados".

Ainda no sentido de prevenir frustrações, todo acontecimento, todas as paradas, atividades e os lugares a serem visitados são rigorosa e constantemente antecipados pelos profissionais do turismo. Além de a programação ser informada constantemente pelo guia e

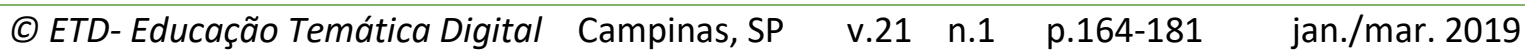


de os recepcionistas dos hotéis explicarem detalhadamente seu funcionamento, horários e atrações, a cada parada nos pontos turísticos, sobrevinham novas orientações: em Curitiba, "A guia acompanha o grupo até a entrada do Jardim Botânico, aponta onde ficam as principais atrações do lugar e recomenda passarmos no Jardim das Sensações." 7 Em frente do Parque Knorr, em Gramado, também conhecido como Aldeia do Papai Noel, o guia dá orientações e recomendações:

\begin{abstract}
Com o grupo de turistas à sua frente, o guia local passa explicações sobre as atrações do Parque, diz que na entrada tem uma escadaria que leva até a fábrica do Papai Noel, por onde iremos caminhar e veremos os ajudantes do Papai Noel. Fala sobre o mirante com vista para um belo vale e sobre a Casa do Papai Noel que encontraremos em seguida, onde seria o centro do Parque. Ele também enfatiza que está tudo sinalizado e o Parque é autointerpretativo, mas que é para percorrermos o trajeto do Parque como um triângulo e, desenhando este trajeto no ar, reforça o que será encontrado em cada ponto. Também faz recomendações para levarmos as máquinas fotográficas e andarmos devagar por causa das raízes no solo, especialmente nos trechos com trilhas. Ao final da explicação, diz para não nos esquecermos de fazer o pedido para o Papai Noel e marca o horário de retorno para uma hora depois. ${ }^{8}$
\end{abstract}

A descrição acima faz lembrar a constatação de Cecília Meireles que, diante de situação parecida, em que o guia orientava incessantemente o olhar e a atenção dos turistas, lamentava: "Impossível, um instante de silêncio e solidão, para se 'sentir' a sala onde os reis sofreram, onde os duques conversaram, onde alguém nasceu ou morreu. Impossível, pararse diante de um objeto para qualquer comunicação sentimental” (MEIRELES, 1998, p. 288). Da mesma forma, perguntamo-nos sobre o tipo de comunicação com os objetos que poderíamos ter frente a tantas 'recomendações' dadas pelo guia ou que aventura nos resta quando tudo já nos é antecipado. Com tantas orientações, soa estranha a fala do guia de que o Parque é autointerpretativo, afinal, mesmo que ainda houvesse muito para o turista descobrir e interpretar, as formas 'corretas` de fazer isso já lhe haviam sido dadas.

Para além do controle dos riscos físicos ou externos - por meio da garantia de estruturas hoteleiras, transporte, informação, organização da programação e dos serviços especializados - na excursão também há uma tentativa de neutralizar outro tipo de risco, ligado ao teor de imprevisibilidade e incertezas de que uma viagem pode fornecer. Entendemos que, mesmo depois de garantida a segurança da viagem, ainda restaria ao viajante muitas formas de se aventurar que já não encontram força para se realizarem no modelo de turismo investigado. Há, por exemplo, muito para se arriscar e se surpreender em relação a outros sabores, espaços, caminhos, arquiteturas e hábitos correspondentes a lugares e culturas diferentes das que conhecia. Muito há para ser descoberto ao se entrar em

\footnotetext{
${ }^{7}$ Diário de Campo 2 (DC 2) - Excursão Natal Encantado em Curitiba.

${ }^{8}$ DC3 - Excursão Gramado e Canela.
} 
um novo museu, contemplar uma obra de arte ou uma paisagem, ou 'perder-se' nos caminhos da viagem. Esta, no entanto, não é uma tarefa fácil, como afirma Benjamin (2012a, p. 73), pois "saber orientar-se numa cidade não significa muito. No entanto, perder-se numa cidade, como alguém se perde numa floresta, exige instrução [...]". Advertência que se expressa na capacidade de apropriação e contemplação necessárias à imaginação de uma nova ordem, diferente daquela predeterminada e milimetricamente controlada. A capacidade de perder-se, mesmo no interior das condições de espaço e tempo que a viagem em excursão oferece, significa a possibilidade de viver uma aventura tal como descreveu Simmel (1998, p. 176): uma forma de experiência "onde uma atividade é retirada totalmente do contexto geral da vida, mas deixa, não obstante, fluir em si a força e a intensidade total da vida".

No caso investigado, a antecipação, a orientação e a condução sobre todas as etapas da viagem e, inclusive, sobre as ações e os pensamentos dos turistas, desestimulam a aventura e a possibilidade de arriscar-se, de se colocar aberto diante do mundo, de ao mesmo tempo retirar-se do "contexto geral da vida" para vivê-la com intensidade. Na excursão, já não se trata apenas de controle sobre os riscos externos para promoção de uma tensão agradável, tal como propuseram Elias e Dunning (1992) em relação às atividades de lazer ${ }^{9}$, mas de controle interno quase absoluto para exatamente evitar que o turista se coloque em tensão, experimente a aventura.

Ainda assim a fala dos turistas continua impregnada pela representação de aventura, especialmente no que diz respeito à possibilidade de encontro com o desconhecido, como diz Robson (Representante comercial, 61 anos), "[...] realmente a viagem deixa a gente fascinado. Tem aquela adrenalina, tu não vês a hora de chegar", e, como explica Fernando (Policial Civil aposentado, 74 anos), "Cada um, quando sai de sua casa, quando pega o táxi, aí começa a aventura, você não sabe o que vem pela frente. Pode ser uma surpresa extremamente agradável ou não tão agradável."

Apesar de as imagens dos lugares turísticos já estarem cristalizadas em nossas consciências, o turista conserva a expectativa em relação à confirmação desta imagem a que pode estar associada a ideia de aventura. Neste caso, o risco que caracteriza tal experiência é a incompatibilidade entre as imagens idealizadas e a realidade encontrada, tal como aconteceu em relação a uma das cidades visitadas. São Joaquim é uma cidade catarinense

\footnotetext{
${ }^{9}$ Segundo a Sociologia das Configurações, de Elias, as atividades de lazer proporcionam uma tensão agradável porque permitem maior liberação das emoções do que nas atividades de tipo sério, porém, dentro dos limites da segurança e dos padrões de civilidade, seriam, assim, "um tipo de excitação que não perturba nem coloca em risco a relativa ordem da vida social" (ELIAS; DUNNING 1992, p. 112).
}

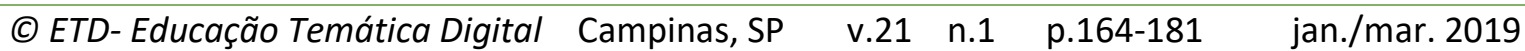


conhecida pelas baixas temperaturas e pela incidência de neve, sendo divulgada pelos veículos de comunicação do Estado por meio de belas paisagens. No entanto, a cidade, bastante pequena e rudimentar, de ruas e calçadas empoeiradas, em nada correspondia à paisagem europeia do imaginário daqueles que ainda não a conheciam, de modo que Fernando expõe sua frustração:

Em termos de turistas, de pessoas que estão indo pela primeira vez, São Joaquim não merece [...] eu achava que era uma cidade pronta para receber os turistas que vêm de várias partes do país e até do exterior, para ver a neve. Chega-se lá e é uma cidade desanimada, sem amor. Levaram-me numa tal de EPAGRI ${ }^{10}$ e ao lado tem um não-sei-o-que da neve, não tem nem um banheiro decente, telhado caindo, mato para todo lado, achei uma vergonha. Eu saí estarrecido, parece gozação aquilo né? Pô, me trazer aqui? É uma cidade triste, rigorosamente triste e você vê o esculacho, não tem uma estrutura nem rudimentar para receber o turista. [...] Eu, sinceramente, saí desanimado. (Fernando, Policial Civil aposentado, 74 anos).

O depoimento sugere que, no âmbito do turismo, constituído como produto para as massas consumidoras em seu período de lazer, o sentido de risco e aventura só poderia se consolidar quando do não atendimento das expectativas do consumidor, ou seja, no não atendimento daquilo que o turista já sabe, que ele já espera e não às descobertas e aos imprevistos de um viajante aventureiro. Essa, aliás, é a forma como os artefatos da indústria cultural seduzem, oferecendo aos consumidores "aquilo que 'eles querem', que já esperam" (VAZ, 2006, p. 28).

Por isso, na excursão, procura-se assegurar também os riscos emocionais, as frustrações e a tensão com o desconhecido. Tais riscos só precisam ser controlados se quem viaja for um cliente e, como tal, um consumidor, que espera ter suas expectativas prévias atendidas, seja em relação ao padrão de conforto das instalações, ao atendimento cordial (pessoal, íntimo) dos profissionais, à paisagem vendida pelo cartão postal e à vivência anunciada na propaganda. De modo geral, a aventura como construção, como percurso (real e simbólico) a ser trilhado pelo sujeito encontra pouco espaço na viagem turística.

Observamos que o caráter de entretenimento, conferido à viagem pelo turismo, constitui-se como necessidade humana, participando do processo de preservação e recuperação da vida, segundo propõe Arendt (2011). No entanto, adverte a autora, quando todos os objetos culturais passam a ser experimentados como entretenimento, ou seja, como bens de consumo, a partir do seu valor de mercadoria, a apropriação, a comoção e a mobilização do pensamento tornam-se inoperantes, restando apenas saciedade de desejos e

10 A Empresa de Pesquisa Agropecuária e Extensão Rural de Santa Catarina (EPAGRI) é uma empresa pública vinculada ao Estado de Santa Catarina. A unidade de São Joaquim, a qual o entrevistado se refere, é uma estação experimental de fruticultura em que são realizadas pesquisas sobre o aprimoramento do cultivo da maçã. Para mais informações sobre a Empresa, ver: <http://www.epagri.sc.gov.br>.




necessidades vitais. Sintoma disto é a demanda permanente por diversão, como desenvolveremos a seguir. Como consequência de as relações com os objetos culturais daremse unicamente pela via do entretenimento, tem-se uma perda importante no âmbito das experiências culturais, que é a incapacidade da comoção subjetiva que ligaria o sentido da obra à realidade, acarretando em alienação em relação ao mundo (ARENDT, 2011).

\section{4 'CARTILHA TURÍSTICA': DIVERSÃO, DISCIPLINA, INFANTILIZAÇÃO}

Da mesma forma que as viagens, inclusive as turísticas, estão impregnadas das representações de aventura, também são consideradas uma possibilidade singular e prestigiosa de diversão. No entanto, diferente da aventura, o turista encontra diversão demasiada durante a viagem, já que este é o propósito em si das atividades de 'tempo livre`. Se considerarmos a diversão como aquilo que desvia a atenção, que distrai, que permite passar o tempo, ou melhor, que serve para 'matar o tempo', como escreveu Adorno (2015), poucas ocupações cumpririam melhor com este propósito do que as viagens turísticas, principalmente as de excursão.

Não por acaso, a viagem assume a função de distração, assim como outras atividades de lazer, mas se diferencia pelo fato de "distrair um pouco mais", como disse Vilson (Técnico em enfermagem aposentado, 64 anos). Com exceção de Edson, um jovem estudante, a maioria dos participantes das excursões que acompanhamos são adultos e idosos aposentados. Embora possuam particularidades, suas rotinas compreendem atividades domésticas, cuidados pessoais, atividades físicas e de lazer, além de compromissos familiares. De modo geral, a vida desses sujeitos se caracteriza por ritmos mais lentos do que estavam acostumados ao longo da vida laboral. Em decorrência disso, demonstram preocupação em se ocupar, falam com orgulho da sua "rotina cheia" (Laura - Dona de casa, aposentada, 64 anos), e explicam que "O negócio é não ficar muito em casa" (Olinda - Do lar, 66 anos).

Não apenas pela quantidade de horas e dias ou pela extensa programação que envolve a atividade - estas seriam as estruturas mais visíveis da diversão -, a tarefa de entreter está colocada em situações muito mais sutis e possui contornos quase imperceptíveis que atravessam a experiência do turista. A primeira exigência para a diversão e, poderíamos dizer para a 'sobrevivência' em um tempo disponível prolongado, seria sabermos o que fazer com ele, 'melhor' do que isso seria que fôssemos orientados sobre o que fazer com ele, o que nos levaria, paradoxalmente, à desobrigação de pensar sobre ele e, ao mesmo tempo, à obrigação de fazer o que é proposto. Como já mencionamos, os guias e demais profissionais cumprem exemplarmente a tarefa de orientar a diversão dos turistas, quando, permanentemente: apontam, sinalizam, recomendam rotas, lugares, direcionam o corpo e o olhar no tempo e no espaço, numa tentativa de assegurar possíveis frustrações e esforços, garantindo que o turista 
verá o que 'deve' ser visto (ou que foi feito para ser visto), e fará o que 'deve` ser feito para divertir-se de forma considerada competente.

Isso fica bastante claro na explicação de Edson (Estudante, 24 anos), sobre o que considera as desvantagens em viajar sozinho, pois "tu não conheces nada, não sabe como chegar aos lugares, onde é bom de ir ou não ir, o que vale a pena ou não vale a pena, onde é bom comer e onde não é bom comer", enquanto que na viagem em excursão "o guia te levava aonde tu querias ir, quer dizer, onde tu deverias ir." (grifos nossos). Realizar a viagem que se deveria mostra que há, de antemão, um dever a cumprir quando se parte em viagem. Esse dever demanda um conjunto de gestos, linguagens e comportamentos próprios que se referem ao cumprimento de horários, à passagem nos pontos turísticos consagrados, à pose adequada para a foto, à compra de souvenir, à preferência pelas descrições objetivas e oficiais sobre as atrações, entre outros. Enfim, um conjunto de disciplinas que temos chamado de 'cartilha turística'.

O que é 'bom', o que 'vale a pena'e o que 'deve` ser feito, ou seja, estar de acordo com o que é determinado pela indústria do turismo, é o que a viagem em excursão assegura. Com as estratégias de antecipação, orientação e condução da subjetividade, ela oferece a garantia da diversão, ou seja, que o turista não corre o risco de frustrar suas expectativas, já que tudo irá "caminhar estreitamente no âmbito das associações habituais" (HORKHEIMER; ADORNO, 2015, p. 31). Se, por um lado, tem-se a certeza de que nada sairá do programado, por outro são minadas as possibilidades do estranhamento e do encontro com o novo, que poderiam suscitar o sentimento de aventura. Ao contrário, para a diversão se realizar

Nenhum esforço de compreensão deve ser exigido, aliás, todo empenho nessa direção deve ser vedado, qualquer relação com o objeto que demande reflexão ou mediação estética para além da superficialidade, deve ser denegada. Aos sentidos humanos é destinado um treinamento que faça responder a demandas específicas, cada vez mais dirigidas e previsíveis. (VAZ, 2006, p. 28).

Por isso, a orientação do guia não cessa na indicação dos objetos turísticos, estendese também à indicação do 'melhor 'registro fotográfico, ou, ao 'mais tradicional', apontando o que 'deve' ser fotografado e sugerindo poses, como aconteceu na viagem a Curitiba:

\footnotetext{
Enquanto aguardávamos a partida dentro do trem Serra do Mar, o guia estimulava as pessoas a fazerem poses debruçadas nas janelas e, posicionado do lado de fora do veículo, fazia o registro fotográfico. Fui convidada por uma turista a ser fotografada junto a ela na tradicional pose na janela do trem. Na minha posição de pesquisadora, mas principalmente de companheira de viagem, senti que mesmo a pretensão de recusa seria desaprovada. ${ }^{11}$
}

\footnotetext{
${ }^{11}$ DC2 - Excursão Natal Encantado em Curitiba. 
Se há no turismo um conjunto de normatizações, fotografar determinados lugares e tirar uma fotografia com quem se está viajando são algumas delas. A orientação do guia em relação a isso garante a diversão, assegurando que, ao mesmo tempo, as expectativas a respeito da viagem sejam cumpridas e também devidamente comprovadas pela imagem. Esses procedimentos só podem assegurar que a viagem que 'deve' ser feita se concretize quando articulados a um comportamento disciplinado dos turistas, os quais, no geral, respondem e obedecem às regras implícitas e explícitas de forma bastante condescendente. Isto se evidencia em relação aos horários (de saída, retorno e de permanência nas atrações turísticas), que devem ser cumpridos com rigidez e, para tanto, os guias exercem cobrança contínua, tal como na viagem para Gramado, quando, dentro do ônibus...

A guia fala que a saída era às $09 \mathrm{~h}$ e já estamos 5 minutos atrasados em função de duas pessoas que ainda não chegaram. Diz que viajar em grupo é ter responsabilidade, tem que cumprir horário e, depois de questionada, repete com a voz aparentemente alterada e impaciente a programação do dia. ${ }^{12}$

A execução da 'cartilha' também pressupõe a realização de deveres relacionados à por onde e como andar e olhar, sendo que a estratégia adotada pelo guia que acompanhou a viagem para Curitiba foi o uso de uma bandeira: "O guia está indicando uma das saídas do Jardim Botânico com a sua bandeira e, contrariado, diz-me que algumas pessoas queriam voltar pelo mesmo lugar que entraram" ${ }^{13} \mathrm{~A}$ irritação deve-se ao fato de que alguns turistas não estavam seguindo o percurso que ele havia proposto e julgava correto, pois nada mais impedia que as pessoas circulassem livremente no espaço, inclusive saindo pelo portão pelo qual havíamos entrado.

Para além da normatização dos horários, da imagem que 'deve`ser fotografada, dos objetos que 'devem 'ser visualizados, e do percurso que 'deve' ser feito para isso, também foram observadas situações em que mesmo as atividades de cunho pessoal eram reguladas, como quando eram 'sugeridos' os momento em que os turistas deveriam tomar banho, descansar e fazer as refeições: "O Guia comenta para aproveitarmos o Café Colonial logo que chegarmos, para dar tempo de descansarmos e, depois, tomarmos banho, pois às $18 \mathrm{~h} 30 \mathrm{~min}$ sairíamos novamente". ${ }^{14}$ No dia seguinte, enfatiza que "todos devem estar almoçando ao meio-dia, para que às $13 \mathrm{~h} 30 \mathrm{~min}$ estejam prontos para o passeio da tarde". ${ }^{15} \mathrm{Em}$ Curitiba, não ser acordado pelo guia não era opção, a escolha era apenas quanto ao horário, ele, então, "Pergunta se queremos que ele nos acorde às $6 \mathrm{~h}$ ou às $6 \mathrm{~h} 30 \mathrm{~min}$. Em coro, as pessoas respondem às $6 h^{\prime \prime} .{ }^{16}$

\footnotetext{
12 DC3 - Excursão Gramado e Canela.

${ }^{13}$ DC2 - Excursão Natal Encantado em Curitiba.

${ }^{14}$ DC1 - Excursão Magia de Natal em Blumenau.

${ }^{15}$ DC1 - Excursão Magia de Natal em Blumenau.

${ }^{16}$ DC2 - Excursão Natal Encantado em Curitiba.

(C) ETD-Educação Temática Digital Campinas, SP $\quad$ v.21 n.1 $\quad$ p.164-181 jan./mar. 2019
} 
Embora algumas regras sejam necessárias para a organização de uma atividade comum a ser realizada por um grande grupo de pessoas, a disciplina exigida vai além de uma necessidade objetiva, ela coincide e se confunde com a própria diversão. A disciplina não só permite que o indivíduo se integre à lógica do consumo e comprove a sua competência no lazer, como garante a adaptação aos ritmos da produção e reprodução mecânica, como afirmam Horkheimer e Adorno (2015). Os esquemas da indústria cultural determinam de tal maneira todos os setores da produção espiritual, que só resta se divertir obedecendo, já que

[...] a mecanização adquiriu tanto poder sobre o homem em seu tempo de lazer e sobre a sua felicidade, determinada integralmente pela fabricação dos produtos de divertimento, que ele apenas pode captar as cópias e as reproduções do próprio processo de trabalho. O pretenso conteúdo é só uma pálida fachada; aquilo que se imprime é a sucessão automática de operações reguladas (HORKHEIMER; ADORNO, 2015, p. 31).

O abandono de si e do próprio pensamento à descontração consiste no exato oposto do que se espera do indivíduo no trabalho. Essa divisão, extremamente racionalizada e rígida entre o lazer e o trabalho é a primeira obrigação que o sujeito deve cumprir, este é o primeiro requisito para que não haja liberdade no 'tempo livre' (ADORNO, 2015). Nesse sentido a diversão já é, de antemão, disciplina, como ensinam Horkheimer e Adorno, pois ela determina os espaços, tempos e as atividades correspondentes à esfera do lazer em relação ao trabalho ${ }^{17}$. Por outro lado, a disciplina intrínseca à viagem (os horários, a organização e a moralidade implícita) consiste na outra face da moeda do mesmo processo de implantação dos ritmos e sentidos do trabalho, sendo por isso que, segundo Adorno (2015, p. 104), o chamado 'tempo livre 'pode ser pensado como paródia de si mesmo, pois "nele se prolonga a não liberdade [...]". Se isso é perceptível entre aqueles que estão ativos no sistema produtivo, parece se impor também para um grupo de pessoas que começou a trabalhar muito cedo, mas também se aposentou precocemente - como se caracterizam os sujeitos do estudo - e hoje, busca ocupar o tempo, paradoxalmente ou não, à semelhança dos ritmos e da rigidez da sociedade do trabalho. Assim como no trabalho em que são elaboradas estratégias para maior disciplina e eficiência dos funcionários, no turismo são previstas punições e premiações conforme o cumprimento ou não das regras estabelecidas. Em Curitiba, no retorno ao ônibus, depois da visita a um ponto turístico:

\footnotetext{
${ }^{17}$ O fato de que o chamado 'tempo livre` - tempo especificamente criado para o lazer - ser um tempo a serviço do mesmo sistema de produção do trabalho e geração de lucros, indica uma convergência de ambos e não uma oposição, bem como a fragilidade da suposta liberdade do primeiro. A crítica de Adorno (2015) é em relação aos conceitos atribuídos ao 'tempo livre`e ao trabalho, não apenas porque o último pode ser prazeroso, ainda que como exceção, mas porque as atividades de lazer podem ser sérias e proporcionar realização, contrapondo a ideia de que deveriam ser vivenciadas ao modo dos hobbies e das pseudoatividades.
}




O guia fala que faltam apenas duas pessoas para entrar no ônibus. Ele procura o telefone na lista de passageiros, mas antes de ligar, as turistas são avistadas caminhando apressadas em direção ao veículo. O guia pede para batermos palmas e cantarmos uma música sobre seu atraso assim que entrarem. As turistas entram no ônibus e caminham em direção a seus assentos, visivelmente constrangidas, ao som das palmas e da canção. ${ }^{18}$

Da mesma forma, o atendimento às regras e o comportamento 'adequado' são enaltecidos, com elogios e palmas do guia e do próprio grupo que demonstra satisfação ao ter seu 'bom comportamento' reconhecido. Talvez mesmo para aqueles que já não fazem parte do sistema trabalhista formal, como é o caso de muitos entrevistados, a viagem ajuda a manter ou recuperar um ritmo sem o qual parecem não conseguir mais viver, tanto que todos colaboram para isso por meio de uma autovigilância e de uma vigilância mútua. Durante a entrevista, seu Arthur (Pedreiro aposentado, 69 anos) expressa a 'necessidade' de os turistas cumprirem os horários durante o lazer de forma tão enfática como no trabalho: "Todos têm horários a cumprir, todos têm relógio. É só ver que o pessoal não está mais ali na frente do hotel e ir para o ônibus [...]. Até acho que a guia podia ser mais enérgica. Não gosto de guia que não seja enérgica. Ela tem que cobrar que o pessoal cumpra o horário."

Se, no geral, o 'tempo livre` não é livre, na excursão é menos ainda, pois, além da autovigilância, há, pelo menos, outras 25 pessoas para contribuir nesta tarefa. Perto do horário de saída da viagem de Florianópolis a Gramado, "a guia sobe ao ônibus dizendo que faltam algumas pessoas. Os senhores sentados próximos a mim comentam que gostam de chegar com antecedência, recriminando, de certa forma, os que chegam 'em cima do laço', nas suas palavras" ${ }^{19} \mathrm{Em}$ outra situação, durante city tour em Curitiba, após a guia anunciar que teremos 20 minutos de passeio em um parque, "Uma pessoa comenta: 'será apenas 10 minutos para descer e 10 minutos para subir'. Outra diz: 'aqui eu não vou nem descer'. Uma terceira contra-argumenta: 'a gente veio para passear, não para dormir', notadamente criticando a fala anterior." ${ }^{20}$ Além da reclamação pelo pouco tempo disponibilizado para conhecer o Parque, chama a atenção como os próprios turistas esperam e exigem determinados comportamentos dos colegas de viagem, o que, implicitamente, repete-se em relação aos momentos de descanso no quarto do hotel e durante as refeições. A expectativa em relação ao comportamento daquele com quem se irá dividir o quarto é expressa por Ivone (Bancária aposentada, 59 anos), que diz "o lado ruim da viagem é tu ter que dormir em um quarto que tu não conheces a outra pessoa. Então tu tens aquela expectativa, às vezes tu dás sorte de se hospedar em um quarto que a pessoa não seja problemática." Nessas situações também são observadas regras de vestimenta, de cuidado com barulhos e de cordialidade

\footnotetext{
${ }^{18}$ DC2 - Excursão Natal Encantado em Curitiba.

${ }^{19}$ DC3 - Excursão Gramado e Canela.

${ }^{20}$ DC2 - Excursão Natal Encantado em Curitiba.
}

(C) ETD-Educação Temática Digital Campinas, SP $\quad$ v.21 n.1 $\quad$ p.164-181 jan./mar. 2019 
que parecem atender a um padrão moral, determinado pela 'competência' a ser demonstrada durante o lazer.

A obediência à 'cartilha turística' limita a autonomia no campo do pensamento e da percepção, o que se verifica pelas reações, não por acaso, extremamente condizente com o que se espera dos turistas. Mesmo antes de ver o objeto turístico, já sabem o que pensar sobre ele e, quando não sabem, são detalhadamente instruídos pelos guias ou por todo o tipo de material impresso (folders, mapas...) distribuído nos espaços visitados. As distinções préestabelecidas sobre os objetos conduzem e automatizam as reações dos turistas, tal como descreve Alain De Botton (2003) em seus relatos de viagem:

Quando os guias elogiavam um local, exerciam pressão sobre o visitante por um entusiasmo que estivesse à altura de seu próprio entusiasmo abalizado. Quando se calavam, o prazer ou interesse pareciam descabidos. Muito antes de entrar no Monastério de Las Descalzas Reales, com suas três estrelas, eu conhecia a opinião oficial com a qual minha reação teria de se harmonizar (DE BOTTON, 2003, p. 124).

A lógica da diversão organizada consiste em habituar os sentidos de tal forma que nem imaginação, nem pensamento, sejam necessários. A repercussão disso consiste na homogeneização dos modos de viver, sentir e experimentar a viagem, de forma que a aceitação sem resistência ao que é oferecido se converte na negação da liberdade que se acredita usufruir durante o lazer:

A libertação prometida pelo entretenimento é a do pensamento como negação. $A$ impudência da pergunta retórica: 'Que é que se quer?' consiste em se dirigir às pessoas fingindo tratá-las como sujeitos pensantes, quando seu fito, na verdade, é o de desabituá-las ao contato com a subjetividade. (HORKHEIMER; ADORNO, 2015, p. 42).

Tendo em vista a dinâmica da excursão, com suas regras, relações e hierarquias (principalmente do guia para com o grupo), o turista não é apenas o consumidor a quem a indústria cultural já privou de subjetividade por meio dos seus mecanismos, mas também, muitas vezes, um 'infante', a quem é negada a opinião ou desconsiderada a sua história. $\mathrm{Na}$ situação investigada, os dados evidenciam uma prática baseada, sobretudo, em um 'pensar por', e concretizada pelas constantes 'lembranças' sobre os remédios que os turistas, principalmente os idosos, devem tomar, as 'sugestões' sobre suas atividades de autocuidado, a 'proposição' sobre a forma e o horário de acordar, mas, principalmente, quando o guia parece como que apresentando o mundo para uma criança, como se o turista já não tivesse sido inserido neste mundo, como se não tivesse história, memória ou saber. Se a criança com frequência é vista ainda como um ser que não fala - no sentido de autonomia, falar por si, como sugerido por Kant (1995) - o velho é alguém que não fala mais. Ambos são, dessa forma, infantilizados. 
Nesse sentido, o serviço dispensado ao turista muito se aproxima daquele que vemos sendo dispensado à população infantil. Não por acaso, o modelo de viagem de excursão é constantemente destinado a grupos de crianças (por meio das viagens pedagógicas escolares) e para os idosos, em turismo. Os turistas da excursão, assim como as crianças, não decidem a hora e o que vão comer, assim como não sabem o valor das refeições, alguém decide e sabe por eles, já que tudo isto foi previamente definido e incluído no valor da excursão. Mais do que isso, sua capacidade decisória é questionada quando o guia pergunta o horário em que deve acordá-los, como se fossem incapazes de cuidar de si, ou quando impõe interpretações prévias sobre os objetos turísticos, como se eles também não conseguissem fazer isso autonomamente, favorecendo as situações de dependência, mesmo quando elas não existem ou não se fazem necessárias.

\section{CONSIDERAÇÕES FINAIS}

Ao mesmo tempo em que o controle dos riscos externos, dado pelo avanço nas condições objetivas relacionadas à infraestrutura na modernidade, permitiu que a viagem fosse praticada como aventura, o turismo frustrou este ímpeto obliterando os riscos inerentes à relação com o novo, o estranho, o desconhecido e o diferente, enfraquecendo as potencialidades formativas que a aventura do deslocamento para longe de casa conservava. Juntamente ao desconforto e perigo da precária estrutura que havia nas viagens clássicas, o turismo retirou do sujeito o ânimo e a coragem do espírito em defrontar-se de forma autônoma consigo mesmo, com os objetos e com o outro, por meio da antecipação, da explicação prévia e do direcionamento ininterrupto do pensar e agir, impedindo que, desta relação arriscada, pois incerta, ainda não necessariamente perigosa, pudesse aventurar-se. 0 único risco ainda inerente à prática turística é o de não se realizar como mercadoria, é não conseguir dar ao turista/consumidor a imagem ou a sensação falsa de que aquele deseja. Ou seja, o risco de fracassar comercialmente.

Sob a crença de que a diversão, circunscrita à lógica da sociedade de massa, concentra os elementos necessários para uma vida feliz e plena, o indivíduo adapta-se mais facilmente a ela e às suas exigências do que a uma busca por aventura de fato. Este modelo de viagem, no entanto, calcado em experiências altamente enrijecedoras do corpo e do espírito repercute na formação de uma subjetividade automatizada, ao ponto de a diversão adquirir as características de uma mercadoria biológica, "sendo necessária à manutenção da vida como o trabalho e o sono, é alimento para ser digerido como o pão, e é, como elemento fundamental de salvaguarda e restauração da vida biológica." (AMBRÓZIO, 2005, p. 108-109).

A infantilização produzida pelo turismo, e que também é, de modo geral, efeito de todo o entretenimento de massa, consiste na limitação da consciência ao automatismo pelo qual se percorrem os roteiros pré-definidos e, também, à necessidade da satisfação imediata




fornecida pelas constantes orientações a apontamentos sobre mais uma bela paisagem, mais um objeto interessante, mais uma saborosa refeição. Com os idosos, o processo ganha outras dimensões, o controle sobre eles assume um caráter tutelar perverso, de negação da autoridade de quem viajou no tempo ${ }^{21}$ e, portanto, possui (possuía) o saber proveniente de suas experiências. A autoridade que tinham os mais velhos e a experiência que passavam para as gerações mais novas nas sociedades tradicionais é retratada por Benjamin por meio da parábola em que um velho

\begin{abstract}
no leito de morte, revela a seus filhos a existência de um tesouro oculto em seus vinhedos. Bastava desenterrá-lo. Os filhos cavam, mas não descobrem qualquer vestígio do tesouro. Com a chegada do outono, porém, as vinhas produzem mais que qualquer outra da região. Só então compreendem que o pai lhes havia transmitido uma certa experiência: a felicidade não está no ouro, mas no trabalho duro (BENJAMIN, 2012c, p.123).
\end{abstract}

O desestímulo à autorreflexão e a negação da autoridade coloca o velho turista numa dupla condição de menoridade em que, a todo o momento, é como se the fosse preciso apresentar o mundo (ainda que apenas na aparência da mercadoria), como se faz com as crianças (ARENDT, 2011). Sair da condição infantilizada na qual se encontram os turistas requer a capacidade de escapar à necessidade de performance no lazer, de que o espírito disponha de alguma autonomia para a construção de outros sentidos, para as experiências vividas, que não os determinados externamente, ou, como observaram Horkheimer e Adorno (2015), de que haja a possibilidade de existirmos, ainda que oprimidos ${ }^{22}$.

\title{
REFERÊNCIAS
}

ADORNO, Theodor Ludwig Wiesengrund. Tempo livre. In: ADORNO, Theodor Ludwig Wiesengrund. Indústria cultural e sociedade. Seleção de textos de Jorge Mattos Brito de Almeida. 9. ed. São Paulo: Paz e Terra, 2015. p. 103-117.

AMBRÓZIO, Júlio. Viagem, turismo, vilegiatura. GEOUSP - Espaço e Tempo, São Paulo, n. 18, p. 105-113, ago. 2005. Disponível em:

http://www.revistas.usp.br/geousp/article/view/73975/77634 Acesso em: 10 out. 2015.

ARENDT, Hannah. Entre o passado e o futuro. 7. ed. São Paulo: Perspectiva, 2011.

BAUMAN, Zygmunt. Europa: uma aventura inacabada. Tradução de Carlos Alberto Medeiros. Rio de Janeiro: Jorge Zahar, 2006.

\footnotetext{
${ }^{21}$ Viajar no tempo, assim como viajar no espaço caracterizavam, respectivamente, o velho camponês sedentário e o marinheiro que viaja por terras distantes, figuras arcaicas da 'experiência' que pelo saber acumulado possuíam autoridade e tinham muito a contar (BENJAMIN, 2012b).

22 Os autores se referiam a um contexto não mais reproduzível, trata-se da Europa pré-fascista, quando, segundo eles, ainda era possível escapar aos mecanismos de mercado tendo em vista o atraso do continente em relação à tendência do monopólio cultural vivida nos países ocidentais (HORKHEIMER; ADORNO, 2015).
}

(C) ETD-Educação Temática Digital Campinas, SP $\quad$ v.21 n.1 $\quad$ p.164-181 jan./mar. 2019 
BENJAMIN, Walter. Infância em Berlin por volta de 1900. In: BENJAMIN, Walter. Rua de mão única. 6. ed. rev. São Paulo: Brasiliense, 2012a. p. 73-145.

BENJAMIN, Walter . O narrador: considerações sobre a obra de Nikolai Leskov. In: BENJAMIN, Walter. Magia e técnica, arte e política: ensaios sobre literatura e história da cultura. 8. ed. rev. São Paulo: Brasiliense, 2012b. p. 213-240.

BENJAMIN, Walter. Experiência e pobreza. In: BENJAMIN, Walter. Magia e técnica, arte e política: ensaios sobre literatura e história da cultura. 8. ed. rev. São Paulo: Brasiliense, 2012c. p. $123-146$.

BERMAN, Marshall. Tudo que é sólido desmancha no ar: a aventura da modernidade. São Paulo: Companhia das Letras, 1987.

DE BOTTON, Alain. A arte de viajar. Rio de Janeiro: Rocco, 2003.

ELIAS, Norbert; DUNNING, Eric. A busca da excitação. Lisboa: DIFEL, 1992.

ENZENSBERGER, Hans Magnus. Com raiva e paciência. Tradução de Lya Luft. Rio de Janeiro: Paz e Terra, 1985.

HORKHEIMER, Max; ADORNO, Theodor Ludwig Wiesengrund. A indústria cultural: o Iluminismo como mistificação das massas. In: ADORNO, Theodor Ludwig Wiesengrund. Indústria cultural e sociedade. Seleção de textos de Jorge Mattos Brito de Almeida. 9. ed. São Paulo: Paz e Terra, 2015. p. 7-74.

KANT, Immanuel. Resposta à pergunta o que é lluminismo. In: KANT, Immanuel. A paz perpétua e outros opúsculos. São Paulo: Edições 70, 1995.

MEIRELES. Cecília. Crônicas de viagem. Rio de Janeiro: Nova Fronteira, 1998. Vol. 1.

ROMANO, Luís Antônio Contatori. Viagens e viajantes: uma literatura de viagens contemporânea. Estação Literária Londrina, v. 10B, p. 33-48, jan. 2013. Disponível em: http://www.uel.br/revistas/uel/index.php/estacaoliteraria/article/view/25719 . Acesso em 10 jan. 2015.

SESC. Serviço Social do Comércio. Contrato de prestação de serviço. Contratante: Verônica Werle. Contratado: Centro de Atividades de Florianópolis. Objeto: Turismo Social Excursões 2014 - Natal de Blumenau - 05 a 07/12. Florianópolis: SESC, 2014.

SIMMEL. Georg. A Aventura. In: SOUZA, Jessé; ÖELZE, Berthold. Simmel e a modernidade. Brasília: UnB. 1998. p. 171-187. Disponível em:

http://www.scribd.com/doc/28055350/Georg-Simmel Acesso em: 11 mar. 2014.

VAZ, Alexandre Fernandez. Lazer, indústria cultural, Biopolítica. In: ISAYAMA, Hélder; LINHALES, Meily Assbú. Sobre lazer e política: maneiras de ver, maneiras de fazer. Belo Horizonte: Ed. da UFMG, 2006. p. 19-40.

Revisão gramatical do texto sob responsabilidade de:

Daiane de Souza Alves Mauricio

E-mail: daiane sam@hotmail.com

(C) ETD-Educação Temática Digital Campinas, SP $\quad$ v.21 n.1 $\quad$ p.164-181 jan./mar. 2019 